\title{
Primitive Retinal Vascular Abnormalities: Tumors and Telangiectasias
}

\author{
Karl Anders Knutsson Umberto De Benedetto Giuseppe Querques \\ Claudia Del Turco Francesco Bandello Rosangela Lattanzio
}

Department of Ophthalmology, San Raffaele Scientific Institute, Milan, Italy

\section{Key Words}

Retinal angiomatosis - Retinal telangiectasias $\cdot$ Retinal vascular tumors • Von Hippel-Lindau syndrome

\begin{abstract}
Primitive retinal vascular abnormalities are benign conditions of the retinal circulation that comprise vascular tumors and telangiectasias. The principal vascular tumors of the retina include retinal capillary hemangioma, cavernous hemangioma of the retina, racemose hemangiomatosis of the retina and retinal vasoproliferative tumor, while primary retinal telangiectasias include Coats' disease, Leber's miliary aneurysms and idiopathic juxtafoveal telangiectasias. In most cases, these alterations result in significant visual impairment due to exudation determined by the structural abnormalities of the retinal vasculature. The aim of this review is to assess the different clinical and diagnostic features of the single pathological entities and to discuss the available treatment modalities including the onset of intravitreal antivascular endothelial growth factor therapy.
\end{abstract}

Copyright $\odot 2012$ S. Karger AG, Basel
(C) 2012 S. Karger AG, Basel

0030-3755/12/2282-0067\$38.00/0

Fax +4161306 1234

E-Mail karger@karger.ch

www.karger.com
Accessible online at: www.karger.com/oph
Primitive retinal vascular abnormalities are benign conditions of the retinal circulation that include vascular tumors and telangiectasias. In many cases, these alterations result in significant visual impairment mainly due to exudation determined by the vascular abnormalities [1]. Treatment modalities are aimed at reducing lesion growth, amount of exudation and to prevent or resolve complications. As these conditions represent a group of heterogeneous diseases, the different clinical and diagnostic features, treatment options and prognosis of the single pathological entities are assessed in this review.

\section{Vascular Tumors of the Retina}

The principal vascular tumors of the retina include retinal capillary hemangioma, cavernous hemangioma of the retina, racemose hemangiomatosis of the retina and retinal vasoproliferative tumor (table 1) [1]. Even though these lesions are classified as benign, exudation, hemorrhages and fibrovascular tissue proliferation may determine retinal detachment associated with severe and permanent visual impairment [1]. Ophthalmologists play a fundamental role in the diagnosis of these alterations, as many vascular tumors of the retina are associated with systemic conditions. 
Table 1. Vascular tumors of the retina: clinical characteristics

\begin{tabular}{llll}
\hline Retinal vascular tumor & Clinical examination & Exudation & Location \\
\hline Capillary hemangioma & Round orange-red lesion & Present & Peripheral retina/juxtapapillary \\
Cavernous hemangioma & Cluster of grapes appearance & Absent & No predilection \\
Vasoproliferative tumor & Pink-yellow mass & Present & Peripheral retina \\
Arteriovenous malformations & Tortuous and dilated vessels & Absent & Optic disk to peripheral retina \\
\hline
\end{tabular}

\section{Retinal Capillary Hemangioma}

Retinal capillary hemangioma, also known as retinal hemangioblastoma, can occur sporadically, or in association with von Hippel-Lindau (VHL) disease $[2,3]$. The prevalence of underlying VHL disease in patients with solitary or multiple retinal capillary hemangioma is reported to be $20-58 \%$ [4]. The mean age of diagnosis of retinal capillary hemangioma is 25 years in patients with VHL disease [5]. Individuals affected by VHL also have a high incidence of renal cell carcinoma, central nervous system hemangiomas, pheochromocytomas and other tumors [3]. Retinal capillary hemangiomas are multiple in about one third of patients, and bilateral in about one half of cases. Patients complain of progressive vision loss, which may be associated with photopsiae.

Ophthalmoscopically a retinal capillary hemangioma appears as a distinct, round, orange-red retinal lesion with feeder vessels [6]. In most cases, intraretinal and subretinal exudation is present. The lesions are typically localized in the mid-peripheral or juxtapapillary retina (fig. 1) [3]. Peripheral lesions are located in the superotemporal and inferotemporal retina and are linked to feeder vessels extending from the optic disk [7]. Fluorescein angiography (FA) typically demonstrates early hyperfluorescence with late leakage and helps distinguish feeding arterioles from draining venules [7]. B scan ultrasonography may be used to estimate total tumor dimensions and the presence of retinal fluid [3]. Optical coherence tomography (OCT) is useful in localizing subretinal fluid and in monitoring the response to treatment [6].

The treatment of these lesions may be challenging, especially in case of multiple and bilateral tumors. Different factors such as size, location, presence of subretinal fluid and visual acuity (VA) must be taken into account before choosing a specific treatment [8].

Observation is recommended in case of small tumors (less than $500 \mu \mathrm{m}$ ) with no subretinal fluid and in case of juxtapapillary retinal capillary hemangioma [9]. Laser photocoagulation is effective in treating retinal capillary hemangiomas that are up to $4.5 \mathrm{~mm}$ in size and is most effective in tumors of $1.5 \mathrm{~mm}$ or smaller [10]. Photocoagulation can be applied directly to the lesion, to the feeder artery or a combination of both techniques can be used [11]. Cryotherapy is recommended when lesions are located anteriorly and are greater than $3 \mathrm{~mm}$ in diameter [6]. Photodynamic therapy (PDT) has also been used to induce occlusion of retinal capillary hemangiomas [9, $12,13]$. For large tumors (size greater than $4 \mathrm{~mm}$ ), or those unresponsive to laser photocoagulation and cryotherapy, plaque radiotherapy has shown good results [14]. Lesions complicated by rhegmatogenous or tractional retinal detachments require vitreoretinal surgery. Systemic and intravitreal administration of inhibitors of vascular endothelial growth factor (VEGF) have shown encouraging results in single case descriptions. This treatment modality may be considered especially in center-involving retinal hemangiomas and can be utilized in combination with PDT [15-17]. However, prospective clinical trials are needed to fully investigate the effects of these treatments, as clinical results are unpredictable [18].

Visual prognosis in patients with retinal capillary hemangioma depends on different variables such as lesion size and number, location and degree of exudation [3]. More than $25 \%$ of eyes develop permanent visual loss and about $20 \%$ have a VA of 20/100 in at least one eye [7]. Patients with multiple tumors have a greater probability of developing a new lesion and thus require more frequent examinations [10]. An early diagnosis and treatment of the condition, prior to onset of symptoms, results in improved visual outcomes [7].

\section{Cavernous Hemangioma of the Retina}

Cavernous hemangiomas of the retina are congenital lesions composed of multiple, thin-walled dilated vascular channels with surface gliosis [19]. They may be sporadic or associated with intracranial cavernous heman- 


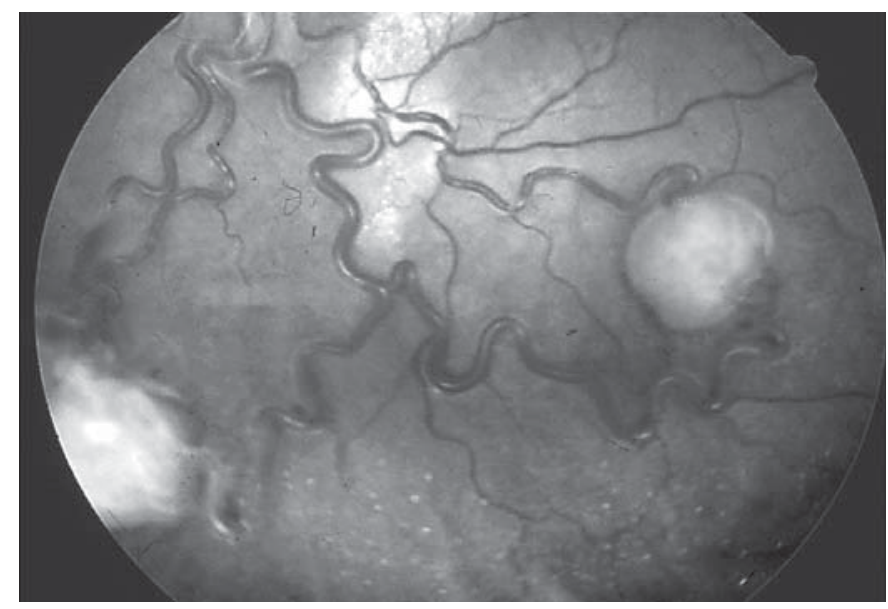

Fig. 1. Red-free image showing the presence of 2 capillary hemangiomas in the inferior midperipheral retina and respective feeder vessels.

giomas and angiomatous skin hamartomas (neuro-oculo-cutaneous syndromes, i.e. phakomatoses) [19, 20]. Patients may be asymptomatic or present reduction of VA if the lesion is located in the macula or associated with vitreous hemorrhage [6].

Ophthalmoscopically the lesion appears as a group of blood-filled saccules resembling a 'cluster of grapes' within the inner retinal layers or on the surface of the optic disk [19]. Subretinal exudation is not present and there are no prominent feeder vessels. FA shows delayed filling during the venous phase due to the low flow system of the tumor. The abnormal blood flow inside the dilated vascular channels determines a separation of erythrocytes from the plasma resulting in hyperfluorescent saccular caps secondary to staining of the plasma component. There is absence of leakage.

Most cavernous hemangiomas of the retina remain stable and can therefore be followed by periodic observation without a specific treatment, even though laser photocoagulation has been described [19].

\section{Retinal Vasoproliferative Tumor}

Retinal vasoproliferative tumors are rare retinal lesions which were initially termed 'presumed acquired retinal hemangiomas' to distinguish them from capillary hemangiomas [21, 22]. Histologically these tumors are composed of glial cells and a network of fine capillaries with some dilated blood vessels [23]. They may be classified as primary ( $74 \%$ of cases) or secondary to different

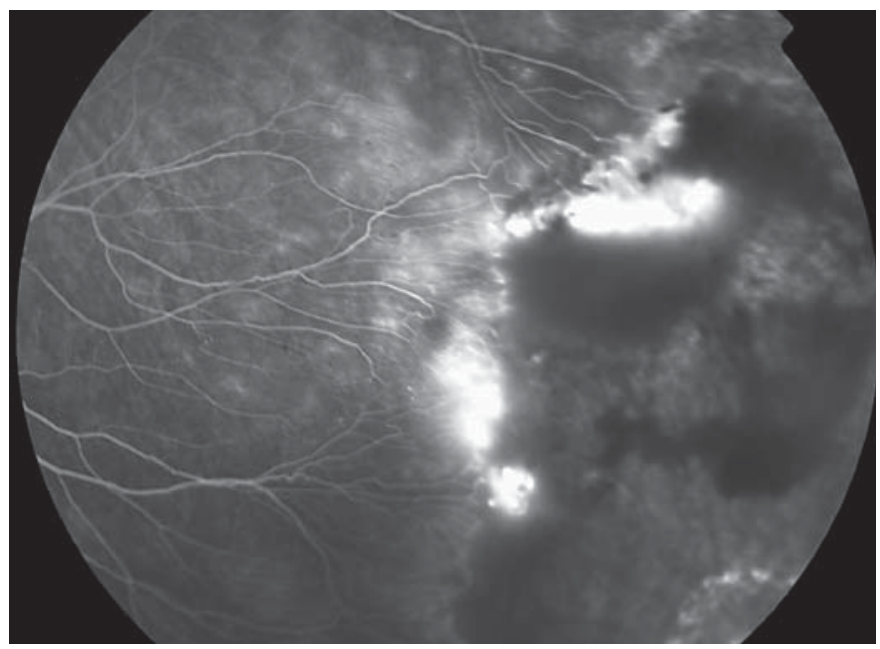

Fig. 2. Vasoproliferative tumor localized in the temporal peripheral retina associated with intraretinal hemorrhages and leakage (FA).

preexisting conditions (26\%) such as inflammatory, vascular, traumatic or degenerative retinal diseases [24]. The mean age of presentation is 30-40 years [24].

On ophthalmological examination, the lesions appear as a pink-yellow raised vascular mass in the inferior peripheral retina and unlike retinal capillary hemangioma do not present feeder vessels. Subretinal exudation is common and occurs in $80 \%$ of cases [24]. FA usually shows rapid filling in the early phases followed by a progressive increase in hyperfluorescence and diffuse leakage in the later phases (fig. 2). Exudative retinal detachment and retinal or vitreous hemorrhage may be associated. Since the lesions are most often peripheral, many patients may be asymptomatic, while others may show symptoms due to retinal exudation.

Small-sized tumors in asymptomatic patients may only require periodic observation. Multiple treatment options are available for the treatment of symptomatic vasoproliferative tumors including laser photocoagulation [24], PDT [25, 26], cryotherapy and plaque brachytherapy $[27,28]$. In the presence of exudative retinal detachment and recurring vitreous hemorrhage, vitreoretinal surgery is necessary. Single case reports describe reduction of tumor thickness and resolution of macular edema after intravitreal injection of bevacizumab [29] and reduction of exudation after ranibizumab [30]. More case descriptions are needed to investigate the potential role of anti-VEGF alone or in combination with other treatment modalities. 
Conservation of VA depends on tumor size, complications such as exudative retinal detachment, vitreous hemorrhage, retinal ischemia, tractional retinal detachment and neovascular glaucoma [24]. Approximately one third of patients can be managed with observation alone. However, even in cases with small peripheral tumors, significant visual loss may occur.

\section{Retinal Arteriovenous Malformation (Wyburn-Mason Syndrome)}

Wyburn-Mason syndrome (also referred to as BonnetDechaumme-Blanc syndrome) is a rare sporadic disorder characterized by congenital arteriovenous malformations (AVMs) affecting predominantly the retina and brain [31]. Other affected tissues may include the skin, bones, muscles, kidneys and gastrointestinal tract $[31,32]$. The retinal lesions are detected incidentally in asymptomatic patients or as a cause of visual impairment.

Ophthalmoscopically retinal AVMs appear as dilated and tortuous retinal vessels extending from the optic disk to the peripheral retina. These malformations have been classified in three groups based upon their severity [33]. Group I AVMs have an abnormal capillary plexus between the major vessels. Group II AVMs do not have a capillary network between artery and vein. Group III AVMs are the most extensive and are characterized by dilated and tortuous vessels and no apparent distinction between the artery and vein. FA demonstrates arteriovenous connections and presence or absence of intervening capillaries between the connections (fig. 3). There is a characteristic absence of leakage, and in the severest cases arteries and veins cannot be differentiated even on angiography.

No direct treatments are available as the dilated vessels extend through great part of the retinal surface. Patients with Wyburn-Mason syndrome are at high risk for severe vision loss due to different mechanisms. Increased vascular tortuosity may lead to vascular occlusions, retinal ischemia and neovascular glaucoma in the later stages [34]. Disease progression can determine optic nerve and retinal nerve fiber layer damage through direct compression or retinal edema $[35,36]$.

\section{Retinal Telangiectasias}

Retinal telangiectasias are a vascular retinal abnormality, characterized by loss of vascular endothelial cells and pericytes with subsequent thickening of the capillary
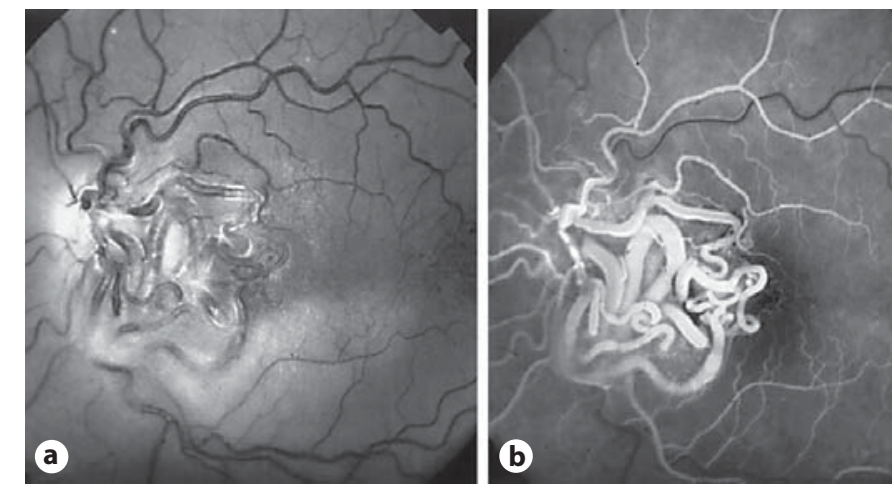

Fig. 3. a Red-free image indicating the presence of AVMs localized in the posterior pole. b FA confirms a characteristic absence of leakage from the lesions.

wall and formation of multiple, saccular and fusiform aneurysms [37]. These changes result in the loss of the blood-retina barrier, causing abnormal vascular permeability and consequent exudation into the intra- or subretinal spaces [38].

Most retinal telangiectasias are acquired, secondary to local or systemic conditions such as branch retinal vein occlusion and diabetic retinopathy [39]. These disorders should be considered in the differential diagnosis and should be excluded before primary retinal telangiectasia is diagnosed.

Based on the age of onset, the ophthalmoscopic features, the progression and the prognosis we can distinguish three different major forms of primary telangiectasia: Coats' disease, Leber's miliary aneurysms, which are a localized, less severe form of Coats' disease, and idiopathic juxtafoveal telangiectasia [39].

\section{Coats' Disease}

Coats' disease affects men 3 times as often as women, in the first or second decade of life, with no racial predilection and is usually unilateral (bilateral in $5 \%$ of cases) [37]. It is usually isolated, but the rare association with some hereditary syndromes such as facioscapulohumeral muscular dystrophy, Turner syndrome or Senior-Loken syndrome suggests the possibility of a genetic component $[40,41]$. Several reports implicate a deficiency of norrin, a retinal protein involved in retinal vasculogenesis in the pathogenesis of Coats' disease $[42,43]$. A mutation in the CRB1 gene has been reported in association with a Coats' disease-like vasculopathy $[44,45]$.

Ophthalmoscopically it is characterized by telangiectatic tortuous retinal vessels with aneurysms that are 
grape-like, clustered or lightbulb shaped [46]. Usually the temporal quadrants are involved and in the initial stages, the posterior pole of the retina may be spared and the patient is asymptomatic [38]. As disease progresses, the vascular abnormalities are associated with increasing amounts of yellow intraretinal and subretinal exudation [38] (fig. 4). The massive exudation often leads to thickening of the retina and exudative detachment. Central vision is usually affected by exudative macular detachment, cystoid macular edema, deposition of subfoveal hard exudates and formation of fibrous scar tissue [38]. Some eyes develop retinal or choroidal neovascularization which may result in vitreous or retinal hemorrhages [39]. The advanced stages of the disease include unilateral leukocoria, exotropia, loss of fixation and painful glaucoma secondary to angle closure [39].

The diagnosis is ophthalmoscopic, but FA is a useful tool to determine the nature and the extent of the vascular abnormalities. In children, Coats' disease is typically diagnosed as a result of poor vision, strabismus or leukocoria and it must be differentiated from other diseases that cause leukocoria in childhood, including retinoblastoma, retinopathy of prematurity, retinal detachment, persistent hyperplastic primary vitreous, congenital cataract, toxocariasis, incontinentia pigmenti, Norrie's disease and familial exudative vitreoretinopathy [38-47].

Less severe forms of Coats' disease, especially in adults, must be differentiated from other disorders that produce vascular changes and exudation; these include inflammatory disorders such as Eales' disease, vasculitis and collagen vascular disease [39]. Tumors accompanied by exudation (i.e. retinoblastoma) may mimic Coats' disease, as may diabetic vasculopathy with lipid deposition, branch retinal vein occlusion with vascular remodeling and edema, rhegmatogenous retinal detachment, radiation retinopathy, idiopathic juxtafoveal telangiectasia, von Hippel's disease, angiomatosis of the retina, exophytic capillary hemangioma and sickle cell retinopathy [46].

Several classifications have been proposed for Coats' disease. Shields and Shields [37] have recently proposed a staging classification, which might help in selecting treatment and predicting the ocular outcomes of the disease (table 2).

Laser photocoagulation is the treatment of choice in mild to moderate cases of exudation from Coats' disease [39-48].

Cryotherapy may be used for the ablation of abnormal retinal vessels [39-48]. If the retina is highly elevated, it may be necessary to drain subretinal fluid in order to flatten the retina and allow sufficient freeze to reach the ret-

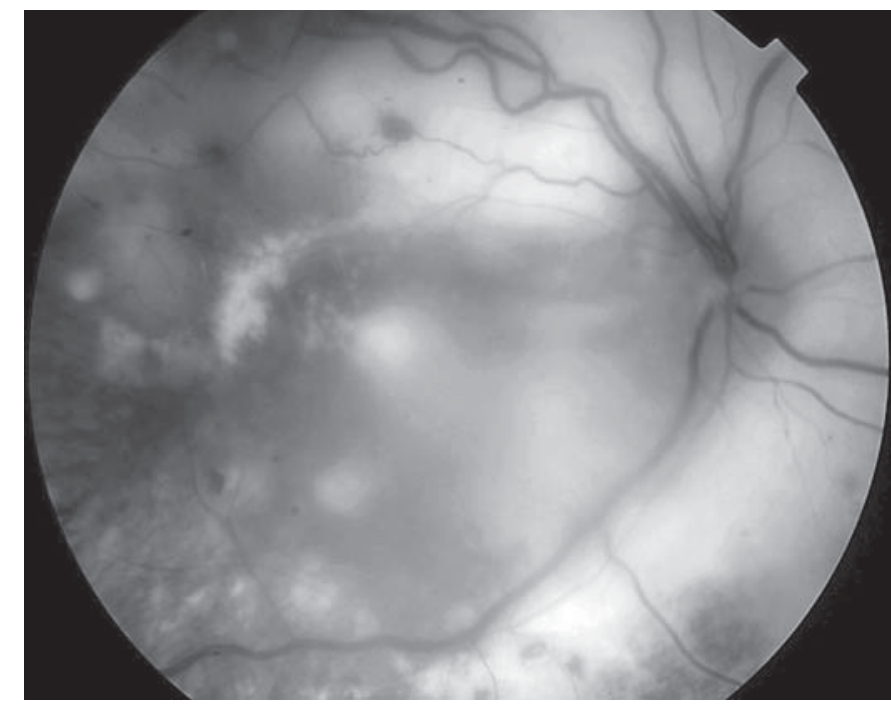

Fig. 4. Massive intraretinal exudation and detachment in a patient affected by Coats' disease.

inal vessels. In these cases, the retina is flattened, and cryotherapy or laser is applied.

In selected cases of Coats' disease with intravitreal proliferation and tractional detachment, vitreous surgery may improve the clinical course. Machemer and Williams [49] reported successful results with vitrectomy and subsequent surgical removal of preretinal membranes and destruction of leaking vessels.

In some instances, enucleation of the affected eye is required. It is useful in case of painful, neovascular glaucoma [38].

Recently, Sun et al. [50] showed elevated levels of VEGF in Coats' disease, which rapidly reduced after injection of pegaptanib sodium. Thus, they suggested that VEGFmediated angiogenesis could play a role in Coats' disease [50].

Venkatesh et al. [51] reported the treatment of 2 older children with Coats' disease with intravitreal bevacizumab injections ( $1.25 \mathrm{mg} / 0.05 \mathrm{ml})$. However, long-term visual outcomes of the use of anti-VEGF agents in children are unknown.

These data suggest that anti-VEGF treatment may be useful for the treatment of Coats' disease. The association with other therapeutic modalities such as laser, cryotherapy and drainage can minimize the need for repeated injections. Prospective multicentric studies are needed to confirm their role in the treatment of Coats' disease and to analyze whether the positive results seen in different studies were due to anti-VEGF treatment, multiple pro- 
Table 2. Coats' disease: classification and management of Shields and Shields [37]

\begin{tabular}{|c|c|c|}
\hline Stage 1 & Retinal telangiectasia only & $\begin{array}{l}\text { Periodic observations or laser photocoagulation } \\
\text { The visual prognosis is usually favorable }\end{array}$ \\
\hline Stage 2 & $\begin{array}{l}\text { Telangiectasia and exudation } \\
\text { A: extrafoveal exudation } \\
\text { B: foveal exudation }\end{array}$ & $\begin{array}{l}\text { Laser photocoagulation or cryotherapy, depending on the extent of disease and } \\
\text { the preference of the ophthalmologist } \\
\text { The prognosis is secondary to the extension of exudation (favorable if limited to } \\
\text { one quadrant or located nasally) } \\
\text { In stage } 2 \mathrm{~A} \text { the visual prognosis is generally good, because the fovea is not } \\
\text { involved in exudation } \\
\text { In stage } 2 \mathrm{~B} \text { the visual prognosis is relatively good if the foveal exudation is not } \\
\text { advanced }\end{array}$ \\
\hline Stage 3 & $\begin{array}{l}\text { Exudative retinal detachment } \\
\text { A: subtotal detachment } \\
\text { B: total retinal detachment }\end{array}$ & $\begin{array}{l}\text { 3A: photocoagulation or cryotherapy; even if the retinal detachment involves the } \\
\text { fovea, it will resolve when the telangiectasia is eradicated } \\
\text { 3B: cryotherapy if the retinal detachment is shallow, but may require an attempt } \\
\text { at surgical reattachment if the detachment is advanced and immediately } \\
\text { posterior to the lens }\end{array}$ \\
\hline
\end{tabular}

cedures done before intravitreal injections or a combination of procedures.

\section{Idiopathic Macular Telangiectasia}

Idiopathic macular telangiectasia (IMT) or idiopathic juxtafoveolar retinal telangiectasis are other forms of telangiectasia involving macular and perifoveal regions without a known cause.

In 1993, Gass and Blodi [52] established a classification of these entities creating three different groups based largely on their clinical and angiographic features and subgroups considering demographic differences or clinical severity. Recently, Yannuzzi et al. [53] proposed a simplified classification of IMT that considers clinical, angiographic features and OCT imaging observations. They described three different groups: type 1 or 'aneurysmal telangiectasia', type 2 or 'perifoveal telangiectasia' and type 3 or 'occlusive telangiectasia' [53].

\section{Type 1 Telangiectasia}

Type 1 telangiectasia is typically unilateral $(97 \%$ of cases) and affects more frequently males than females.

On biomicroscopy, prominent easily visible telangiectatic retinal capillaries, with variable-sized aneurysmal dilations are a consistent hallmark of this type of IMT $[52,53]$ and are located usually temporal to the fovea. Macular edema and lipid deposition are characteristic features. Central macular edema is evident angiographically and confirmed with OCT in all cases. There is no evidence of preretinal or subretinal neovascularization (SRNV). Although a vascular lesion in the juxtafoveal area is essential for diagnosis, this group of telangiectasias may also develop local vascular changes in the midperipheral fundus.

The vascular malformations may function normally for years and then progress to a pathological state later in life [52-54]. If macular edema and exudation occur, patients could complain of visual worsening. The median VA at presentation is 20/40 [53]. Laser photocoagulation may be effective in reducing the exudation and improving or stabilizing vision. Other treatment options are intravitreal steroid injections or anti-VEGF agents.

Intravitreal injections of triamcinolone acetonide are effective in reducing macular edema reducing the production of VEGF and stabilizing the blood-retina barrier [55-57].

Bevacizumab intravitreal injection resulted in an improvement of VA and in a reduction of FA macular leakage and macular edema [58].

\section{Type 2 Telangiectasia}

Idiopathic macular telangiectasia (MacTel) type 2 is the most common type of IMT. It is acquired and affects middle-aged patients $[52,53]$. Males and females are af- 


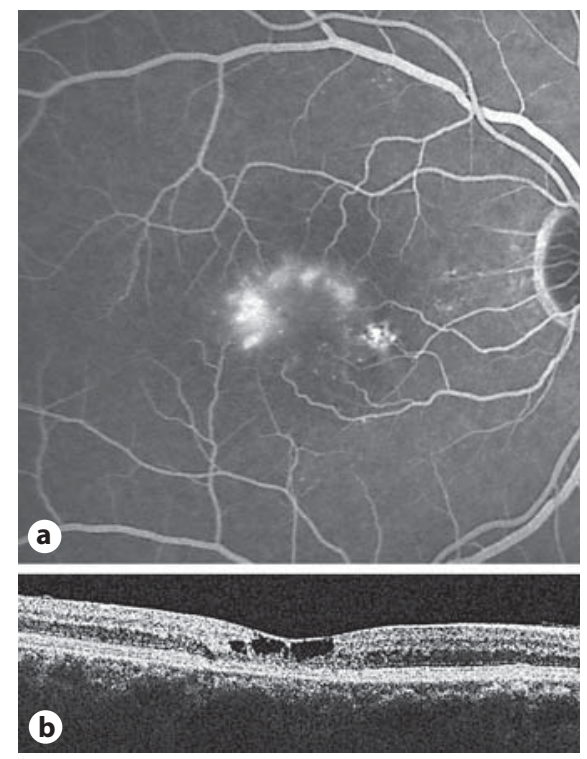

Fig. 5. a FA indicating the presence of IMT (MacTel) type 2 . b OCT showing the presence of pseudocystic lesions at the fovea without retinal thickening.

fected equally. This disorder is bilateral, but may be asymmetric appearing as unilateral in its early stages. There are some typical characteristics of this IMT: the absence of prominent aneurysms or hemorrhage $[52,53]$, the absence of macular edema or lipid exudation (unless SRNV has developed) and the presence of foveolar atrophy. Foveal atrophy is the primary cause of visual impairment, distinguishable from the rapid and severe visual loss that may occur with the advent of SRNV and fibrosis.

Yannuzzi et al. [53] simplified the 5 Gass and Blodi stages into 2 distinct stages that have clinical, prognostic and therapeutic implications: a nonproliferative stage (stages 1-4), characterized by telangiectasis and foveal atrophy without SRNV, and a proliferative stage (stage 5), defined by the advent of SRNV and fibrosis.

Nonproliferative IMT II is characterized by an angiographic late intraretinal staining pattern (fig. 5). In the past, many ophthalmologists interpreted it as macular edema secondary to retinal vascular leakage. Today it is well demonstrated that argon laser photocoagulation is not effective in the treatment of nonproliferative IMT II [52-59]. Gass and Blodi [52] reported that laser treatment resulted in either worsened or no change in VA. In addition, treatment was associated with retinal pigment epithelial changes, posttreatment retinal hemorrhages, vascularized retinal scars and increased retinal vascular distortion [59].

Primitive Retinal Vascular Abnormalities
Verteporfin PDT was also tried in patients with nonproliferative IMT II in an attempt to reduce the permeability of the telangiectatic vessels [60]. However, PDT improved neither vision nor the macular edema and appeared therefore not effective.

In nonproliferative IMT II the loss of vision is primarily due to foveal atrophy rather than exudation, so it is not surprising that laser treatment could not have a role in the treatment of this pathology. For the same reasons also intravitreal triamcinolone acetonide is likely to have a minor or no therapeutic effect in nonproliferative IMT II [61-63].

Recent publications on intravitreal bevacizumab injections report on possible short-term VA increase, a short-term decrease in retinal thickness and a reduction in angiographic leakage in some cases of IMT IIA [6467]. Retreatment is less effective and a rebound effect after the initial two injections was supposed [68].

A more recent and larger retrospective review of 9 eyes treated with intravitreal bevacizumab and followed for 2 years corroborated that intravitreal bevacizumab decreased FA leakage but had no short-term effect on VA or OCT appearance [69]. Similar results to these two reports were observed with intravitreal injections of pegaptanib [70]. These studies suggest that eyes with minimal changes on OCT do not show functional improvement despite repeated intravitreal anti-VEGF injections $[70,71]$ and that there seems to be no apparent VA or OCT benefit to using intravitreal anti-VEGF in the absence of SRNV [69-71].

Before the advent of VEGF antagonists, therapeutic options for SRNV associated with IMT II included laser photocoagulation, PDT with or without intravitreal triamcinolone acetonide, transpupillary thermotherapy and surgical removal of the SRNV [72-78].

Verteporfin PDT was reported to produce SRNV obliteration in IMT II but with modest visual results [73, 74, 79]. Combined PDT and intravitreal triamcinolone acetonide of $4 \mathrm{mg}$ has shown short-term visual acuity improvement [80].

Transpupillary thermotherapy has also been reported to be effective in stabilizing or improving the visual function in 12 of 13 eyes with SRNV secondary to IMT II [77, 78].

Surgical removal of subfoveal SRNV was attempted by Berger et al. [72] in two patients with IMT IIA resulting in poor postoperative visual outcome.

The anti-VEGF approach is a reasonable treatment alternative for proliferative IMT II. Several case series in the literature investigated the effects of bevacizumab or

Ophthalmologica 2012;228:67-77 


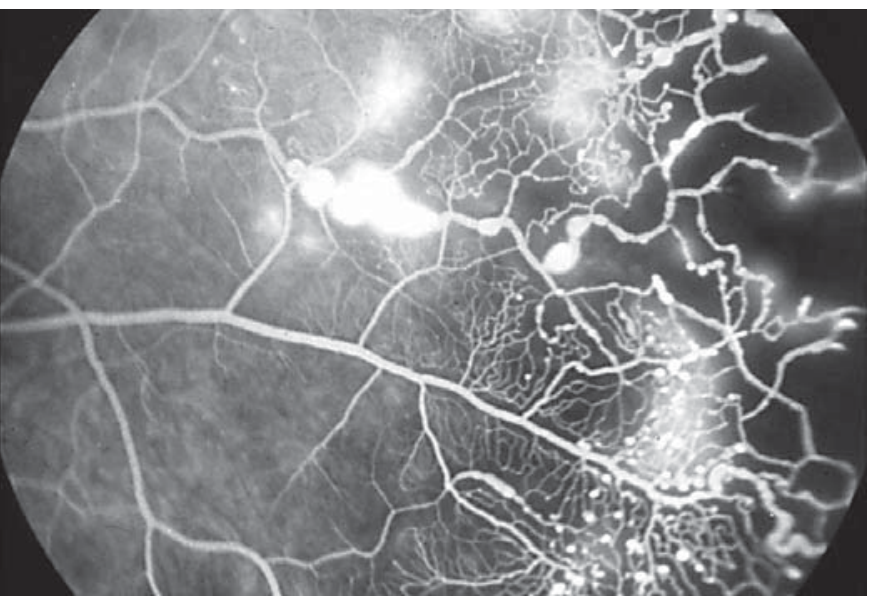

Fig. 6. FA indicating the presence of Leber's miliary aneurysms in the temporal hemiretina.

ranibizumab but with limited (12 months or less) followup [80-87]. A single injection of intravitreal bevacizum$\mathrm{ab}(1.25 \mathrm{mg})$ seems to be effective to improve VA and to decrease mean central foveal thickness. Several case reports of treatment with one or more intravitreal injections of bevacizumab $(1.25 \mathrm{mg})[81,82,84]$ or ranibizumab $(0.5 \mathrm{mg})[85,86]$ injections with a mean 6 -month follow-up corroborated the improvement in VA, the resolution of subretinal and intraretinal fluid on OCT and the regression of SRNV with cessation of SRNV leakage in all cases. On the other hand, in a more recent retrospective series of 5 eyes with proliferative idiopathic juxtafoveolar retinal telangiectasis II treated with intravitreal bevacizumab with a longer follow-up (2 years), bestcorrected VA was unchanged or improved after treatment [69].

Primary treatment with combined intravitreal injections of bevacizumab $(1.25 \mathrm{mg})$ [88] or ranibizumab (0.5 $\mathrm{mg}$ ) and PDT [89] were also reported with an improvement of VA and regression of SRNV confirmed by clinical, FA and OCT findings.

In conclusion, current preliminary results suggest that intravitreal delivery of anti-VEGF therapy combined with or without PDT appears efficacious and should be considered as a treatment option for proliferative IMT II. Long-term follow-up and larger series are needed to address the long-term outcomes, the needed frequency of anti-VEGF drug delivery, and specific side effects or complications of anti-VEGF therapy in this condition.

\section{Type 3 Telangiectasia}

Type 3 telangiectasia is a rare form of IMT described by Gass and Blodi [52], characterized by progressive bilateral perifoveolar capillary obliteration, capillary telangiectasis, minimal exudation clinically and on FA and visual loss in association with systemic or cerebral familial disease such as polycythemia, hypoglycemia, gouty arthritis, ulcerative colitis, multiple myeloma and chronic lymphocytic leukemia. After the initial description, no other reports of this entity have been described in the literature.

\section{Leber's Miliary Aneurysm}

Leber's miliary aneurysm represents the third group of retinal primary telangiectasiae. Generally, it is unilateral, and appears in males with no racial predilection [88, 89] around the fourth decade of life. The most frequent localization is the temporal hemiretina between the posterior pole and the peripheral retina. The diagnosis is made with a funduscopy and FA, showing multiple saccular or fusiform aneurysms confined to 1 or 2 quadrants near the equatorial region (fig. 6). Usually focal chronic extravasation with hard exudates is present. Because of its midperipheral location, usually patients do not complain of visual impairment. In the early phase of FA there is hyperfluorescence of vascular dilatations and at the later stage a diffusion of contrast from the telangiectasias, which may cause cystoid macular edema [90].

Differential diagnoses that must be considered are other primary and secondary retinal aneurysms. In contrast to Leber's aneurysms, juxtafoveal telangiectasias appear in the posterior pole and generally in people over 40 years of age [91]. Forms of Coats' disease have been described in adults with smaller functional repercussions, but the number of aneurysms and exudates is much greater than in Leber's aneurysms [92]. Retinal arterial macroaneurysm is more frequent in women and is associated with high blood pressure.

The treatment of Leber's miliary aneurysms is similar to type I IMT. If the area of telangiectasis is limited to 1 quadrant without significant lipid accumulation, observation of the lesions on a 3- to 6-month basis is recommended [90, 93-95]. When there is macular involvement, the treatment relies on argon laser photoablation of the aneurysms [90-92, 95]. The conversion to Coats' disease has been reported. The progression is variable, so for these patients continuous monitoring is recommended $[93,94]$. 


\section{Conclusions}

Primitive retinal vascular abnormalities comprehend vascular tumors and telangiectasias. These alterations are often characterized by significant visual impairment mainly caused by increased permeability due to structural anomalies of the retinal vessels. If left untreated, chronic macular edema and exudation can lead to drastic complications such as retinal detachment and consequent neovascular glaucoma. Furthermore, chronic ede- ma left untreated leads to irreversible macular atrophy and permanent loss of vision. Clinical, FA and OCT findings aid the diagnosis of these conditions and offer important information regarding the disease and eventual therapeutic management. The current therapeutic strategies are aimed at reducing lesion growth, amount of exudation and to prevent or resolve complications. Primary treatments aimed against these vascular lesions include laser photocoagulation, intravitreal injection of antiVEGF drugs, cryotherapy and PDT.

\section{References}

1 Maher ER, Kaelin WG Jr: Von Hippel-Lindau disease. Medicine (Baltimore) 1997;76: 381-391.

2 Maher ER, Webster AR, Moore AT: Clinical features and molecular genetics of von Hippel-Lindau disease. Ophthalmic Genet 1995; 16:79-84

-3 Singh AD, Shields CL, Shields JA: Von Hippel-Lindau disease. Surv Ophthalmol 2001; 46:117-142.

4 Singh A, Shields J, Shields C: Solitary retinal capillary hemangioma: hereditary (von Hippel-Lindau disease) or nonhereditary? Arch Ophthalmol 2001;119:232-234.

5 Maher ER, Yates JR, Harries R, Benjamin C, Harris R, Moore AT, Ferguson-Smith MA: Clinical features and natural history of von Hippel-Lindau disease. Q J Med 1990;77: 1151-1163.

6 Singh A: Intraocular vascular tumors. Saudi J Ophthalmol 2007;21:25-34.

7 Webster AR, Maher ER, Moore AT: Clinical characteristics of ocular angiomatosis in von Hippel-Lindau disease and correlation with germline mutation. Arch Ophthalmol 1999; 117:371-378.

-8 Singh AD, Nouri M, Shields CL, Shields JA, Perez N: Treatment of retinal capillary hemangioma. Ophthalmology 2002;109:17991806.

$\checkmark 9$ Schmidt-Erfurth UM, Kusserow C, Barbazetto IA, Laqua H: Benefits and complications of photodynamic therapy of papillary capillary hemangiomas. Ophthalmology 2002;109:1256-1266.

10 Schmidt D, Natt E, Neumann HP: Longterm results of laser treatment for retinal angiomatosis in von Hippel-Lindau disease. Eur J Med Res 2000;5:47-58.

-11 Blodi CF, Russell SR, Pulido JS, Folk JC: Direct and feeder vessel photocoagulation of retinal angiomas with dye yellow laser. Ophthalmology 1990;97:791-795, discussion 796-797.

12 Atebara NH: Retinal capillary hemangioma treated with verteporfin photodynamic therapy. Am J Ophthalmol 2002;134:788-790.
Bakri SJ, Sears JE, Singh AD: Transient closure of a retinal capillary hemangioma with verteporfin photodynamic therapy. Retina 2005;25:1103-1104.

14 Kreusel KM, Bornfeld N, Lommatzsch A, Wessing A, Foerster MH: Ruthenium-106 brachytherapy for peripheral retinal capillary hemangioma. Ophthalmology 1998; 105:1386-1392.

15 Ach T, Thiemeyer D, Hoeh AE, Schaal KB, Dithmar S: Intravitreal bevacizumab for retinal capillary haemangioma: longterm results. Acta Ophthalmol 2010;88:e137-e138.

16 Mennel S, Meyer CH, Callizo J: Combined intravitreal anti-vascular endothelial growth factor (Avastin) and photodynamic therapy to treat retinal juxtapapillary capillary haemangioma. Acta Ophthalmol 2010;88: 610-613.

17 Michels S, Messmer E, Sutter F, Kurz-Levin MM: Intravitreal anti-VEGF therapy for capillary hemangioblastomas in von HippelLindau disease. Klin Monatsbl Augenheilkd 2008;225:292-294.

18 Wong WT, Liang KJ, Hammel K, Coleman HR, Chew EY: Intravitreal ranibizumab therapy for retinal capillary hemangioblastoma related to von Hippel-Lindau disease. Ophthalmology 2008;115:1957-1964.

19 Gass JD: Cavernous hemangioma of the retina. A neuro-oculo-cutaneous syndrome. Am J Ophthalmol 1971;71:799-814.

20 Turell ME, Singh AD: Vascular tumors of the retina and choroid: diagnosis and treatment. Middle East Afr J Ophthalmol 2010;17:191200.

21 Baines PS, Hiscott PS, McLeod D: Posterior non-vascularized proliferative extraretinopathy and peripheral nodular retinal telangiectasis. Trans Ophthalmol Soc UK 1982;102: 487-491.

22 Shields JA, Decker WL, Sanborn GE, Augsburger JJ, Goldberg RE: Presumed acquired retinal hemangiomas. Ophthalmology 1983; 90:1292-1300.
23 Irvine F, O'Donnell N, Kemp E, Lee WR: Retinal vasoproliferative tumors: surgical management and histological findings. Arch Ophthalmol 2000;118:563-569.

24 Shields CL, Shields JA, Barrett J, De Potter P: Vasoproliferative tumors of the ocular fundus. Classification and clinical manifestations in 103 patients. Arch Ophthalmol 1995; 113:615-623.

25 Blasi MA, Scupola A, Tiberti AC, Sasso P, Balestrazzi E: Photodynamic therapy for vasoproliferative retinal tumors. Retina 2006; 26:404-409.

26 Saldanha MJ, Edrich C: Treatment of vasoproliferative tumors with photodynamic therapy. Ophthalmic Surg Lasers Imaging 2008;39:143-145.

27 Anastassiou G, Bornfeld N, Schueler AO, Schilling H, Weber S, Fluehs D, Jurklies B, Vij O, Sauerwein W: Ruthenium-106 plaque brachytherapy for symptomatic vasoproliferative tumours of the retina. Br J Ophthalmol 2006;90:447-450.

28 Cohen VM, Shields CL, Demirci H, Shields JA: Iodine-125 plaque radiotherapy for vasoproliferative tumors of the retina in 30 eyes. Arch Ophthalmol 2008;126:1245-1251.

29 Kenawy N, Groenwald C, Damato B: Treatment of a vasoproliferative tumour with intravitreal bevacizumab (Avastin). Eye (Lond) 2007;21:893-894.

30 Makdoumi K, Crafoord S: Vasoproliferative retinal tumours in a Swedish population. Acta Ophthalmol 2011;89:91-94.

31 Wyburn-Mason R: Arteriovenous aneurysm of midbrain and retina, facial nevi and mental changes. Brain Dev 1943;66:163-203.

32 Theron J, Newton TH, Hoyt WF: Unilateral retinocephalic vascular malformations. Neuroradiology 1974;7:185-196.

- 33 Archer DB, Deutman A, Ernest JT, Krill AE: Arteriovenous communications of the retina. Am J Ophthalmol 1973;75:224-241.

- 34 Bech K, Jensen OA: On the frequency of coexisting racemose haemangiomata of the retina and brain. Acta Psychiatr Scand 1961; $36: 47-56$. 
-35 Effron L, Zakov ZN, Tomsak RL: Neovascular glaucoma as a complication of the Wyburn-Mason syndrome. J Clin Neuroophthalmol 1985;5:95-98.

- 36 Shah GK, Shields JA, Lanning RC: Branch retinal vein obstruction secondary to retinal arteriovenous communication. Am J Ophthalmol 1998;126:446-448.

- 37 Shields JA, Shields CL: Coats' disease: the 2001 Lu Esther T. Mertz lecture. Retina 2002; 22:80-91.

- 38 Jones JH, Kroll AJ, Lou PL, Ryan EA: Coats' disease. Int Ophthalmol Clin 2001;41:189198.

39 Do DV, Haller JA: Coats' disease and retinal telangiectasia; in Yanoff M, Duker JS (eds): Ophthalmology, ed 3. Maryland heights, Mosby, 2008, chapt 6.22.

40 Destro M, Gragoudas ES: Coats' disease: natural history and results of treatment. Am J Ophthalmol 1965;60:855-865.

41 Arrigg PG, Lahav M, Hutchins RK, Weiter JJ: Pigmentary retinal degeneration and Coats' disease: a case study. Ophthalmic Surgery 1998;19:432-435.

-42 Black GC, Perveen R, Bonshek R, Cahill M, Clayton-Smith J, Lloyd IC, McLeod D: Coats' disease of the retina (unilateral retinal telangiectasis) caused by somatic mutation in the NDP gene: a role for norrin in retinal angiogenesis. Hum Mol Genet 1999;8:2031-2035.

-43 Rehm HL, Gutiérrez-Espeleta GA, Garcia R, Jiménez G, Khetarpal U, Priest JM, Sims KB, Keats BJ, Morton CC: Norrie disease gene mutation in a large Costa Rican kindred with a novel phenotype including venous insufficiency. Hum Mutat 1997;9:402-408.

44 Robitaille JM, Monsein L, Traboulsi EI: Coats' disease and central nervous system venous malformation. Ophthalmic Genet 1996;17:215-218.

45 Chiu SL, Chen SN, Chen YT, Chen PJ: Coats' disease and neovascular glaucoma in a child with neurofibromatosis. J Pediatr Ophthalmol Strabismus 2010;26:1-3.

46 Reichstein DA, Recchia FM: Coats disease and exudative retinopathy. Int Ophthalmol Clin 2011;51:93-112.

-47 François J: Neonatal or juvenile leucocoria. Ophthalmologica 1979;179:129-141.

-48 Smithen LM, Brown GC, Brucker AJ, Yannuzzi LA, Klais CM, Spaide RF: Coats' disease diagnosed in adulthood. Ophthalmology 2005;112:1072-1078.

49 Machemer R, Williams JM: Pathogenesis and therapy of traction detachment in various retinal vascular diseases. Am J Ophthalmol 1988;105:170-181.

-50 Sun Y, Jain A, Moshfeghi DM: Elevated vascular endothelial growth factor levels in Coats disease: rapid response to pegaptanib sodium. Graefes Arch Clin Exp Ophthalmol 2007;245:1387-1388.

51 Venkatesh P, Mandal S, Garg S: Management of Coats disease with bevacizumab in 2 patients. Can J Ophthalmol 2008;43:245-246.
52 Gass JD, Blodi BA: Idiopathic juxtafoveolar retinal telangiectasis. Update of classification and follow-up study. Ophthalmology 1993;100:1536-1546.

53 Yannuzzi LA, Bardal AM, Freund KB, Chen KJ, Eandi CM, Blodi B: Idiopathic macular telangiectasia. Arch Ophthalmol 2006;124: 450-460.

54 Gass JD, Oyakawa RT: Idiopathic juxtafoveolar retinal telangiectasis. Arch Ophthalmol 1982;10:769-780.

55 Wilson CA, Berkowitz BA, Sato Y, Ando N, Handa JT, de Juan E Jr: Treatment with intravitreal steroid reduces blood-retinal barrier breakdown due to retinal photocoagulation. Arch Ophthalmol 1992;110:1155-1159.

56 Edelman JL, Lutz D, Castro MR: Corticosteroids inhibit VEGF-induced vascular leakage in a rabbit model of blood-retinal and blood-aqueous barrier breakdown. Exp Eye Res 2005;80:249-258.

57 Li KK, Goh TY, Parsons H, Chan WM, Lam DS: Use of intravitreal triamcinolone acetonide injection in unilateral idiopathic juxtafoveal telangiectasis. Clin Experiment Ophthalmol 2005;33:542-544.

58 Gamulescu MA, Walter A, Sachs H, Helbig $\mathrm{H}$ : Bevacizumab in the treatment of idiopathic macular telangiectasia. Graefes Arch Clin Exp Ophthalmol 2008;246:1189-1193.

59 Park DW, Schatz H, McDonald HR, Johnson $\mathrm{RN}$ : Grid laser photocoagulation for macular edema in bilateral juxtafoveal telangiectasis. Ophthalmology 1997;104:1838-1846.

60 De Lahitte GD, Cohen SY, Gaudric A: Lack of apparent short-term benefit of photodynamic therapy in bilateral, acquired, parafoveal telangiectasis without subretinal neovascularization. Am J Ophthalmol 2004;138: 892-894.

61 Alldredge CD, Garretson BR: Intravitreal triamcinolone for the treatment of idiopathic juxtafoveal telangiectasis. Retina 2003;23: 113-116.

62 Martinez JA: Intravitreal triamcinolone acetonide for bilateral acquired parafoveal telangiectasis. Arch Ophthalmol 2003;121: 1658-1659.

63 Cakir M, Kapran Z, Basar D, Utine CA, Eroglu F, Perente I: Optical coherence tomography evaluation of macular edema after intravitreal triamcinolone acetonide in patients with parafoveal telangiectasis. Eur J Ophthalmol 2006;16:711-717.

64 Charbel Issa P, Holz FG, Scholl HP: Findings in fluorescein angiography and optical coherence tomography after intravitreal bevacizumab in type 2 idiopathic macular telangiectasia. Ophthalmology 2007;114:17361742.

65 Moon SJ, Berger AS, Tolentino MJ, Misch DM: Intravitreal bevacizumab for macular edema from idiopathic juxtafoveal retinal telangiectasis. Ophthalmic Surg Lasers Imaging 2007;38:164-166.
66 Querques G, Delle Noci N: Optical coherence tomography findings in nonproliferative group 2a idiopathic juxtafoveal retinal telangiectasis. Retina 2008;28:368-369.

67 Querques G, Delle Noci N: Juxtafoveal telangiectasias. Ophthalmology 2008;115:1636.

68 Charbel Issa P, Finger RP, Holz FG, Scholl HP: Eighteen-month follow-up of intravitreal bevacizumab in type 2 idiopathic macular telangiectasia. $\mathrm{Br} J$ Ophthalmol 2008;927: 941-945.

69 Kovach JL, Rosenfeld PJ: Bevacizumab (Avastin) therapy for idiopathic macular telangiectasia type II. Retina 2009;29:27-32.

70 Vianna RN, Squeri G, Turquetti R, Brasil OF, Burnier MN Jr: Intravitreal pegaptanib reduces fluorescein leakage in idiopathic parafoveal telangiectasis. Can J Ophthalmol 2008;43:492-493.

-71 Gamulescu MA, Walter A, Sachs H, Helbig $\mathrm{H}$ : Bevacizumab in the treatment of idiopathic macular telangiectasia. Graefes Arch Clin Exp Ophthalmol 2008;246:11891193.

72 Berger AS, McCuen BW 2nd, Brown GC, Brownlow RL Jr: Surgical removal of subfoveal neovascularization in idiopathic juxtafoveolar retinal telangiectasis. Retina 1997; 17:94-98.

73 Potter MJ, Szabo SM, Chan EY, Morris AH: Photodynamic therapy of a subretinal neovascular membrane in type $2 \mathrm{~A}$ idiopathic juxtafoveolar retinal telangiectasis. Am J Ophthalmol 2002;133:149-151.

-74 Snyers B, Verougstraete C, Postelmans L, Leys A, Hykin P: Photodynamic therapy of subfoveal neovascular membrane in type $2 \mathrm{~A}$ idiopathic juxtafoveolar retinal telangiectasis. Am J Ophthalmol 2004;137:812-819.

75 Hershberger VS, Hutchins RK, Laber PW: Photodynamic therapy with verteporfin for subretinal neovascularization secondary to bilateral idiopathic acquired juxtafoveolar telangiectasis. Ophthalmic Surg Lasers Imaging 2003;34:318-320.

76 Alldredge CD, Garretson BR: Intravitreal triamcinolone for the treatment of idiopathic juxtafoveal telangiectasis. Retina 2003;23: 113-116.

77 Shukla D, Singh J, Kolluru CM, Kim R, Namperumalsamy $\mathrm{P}$ : Transpupillary thermotherapy for subfoveal neovascularization secondary to group 2A idiopathic juxtafoveolar telangiectasis. Am J Ophthalmol 2004;138:147-149.

78 Nachiappan K, Shanmugam MP: Treatment of CNVM secondary to idiopathic juxtafoveal retinal telangiectasis by transpupillary thermotherapy. Am J Ophthalmol 2005;139: 577-578.

79 Potter MJ, Szabo SM, Sarraf D, Michels R, Schmidt-Erfurth U: Photodynamic therapy for subretinal neovascularization in type $2 \mathrm{~A}$ idiopathic juxtafoveolar telangiectasis. Can J Ophthalmol 2006;41:34-37. 
80 Mandal S, Venkatesh P, Abbas Z, Vohra R, Garg S: Intravitreal bevacizumab (Avastin) for subretinal neovascularization secondary to type $2 \mathrm{~A}$ idiopathic juxtafoveal telangiectasia. Graefes Arch Clin Exp Ophthalmol 2007;245:1825-1829.

81 Jorge R, Costa RA, Calucci D, Scott IU: Intravitreal bevacizumab (Avastin) associated with the regression of subretinal neovascularization in idiopathic juxtafoveolar retinal telangiectasis. Graefes Arch Clin Exp Ophthalmol 2007;245:1045-1048.

82 Shanmugam MP, Mythri HM, Shetty NS: Intravitreal bevacizumab for parafoveal telangiectasia-associated choroidal neovascular membrane. Indian J Ophthalmol 2007;55: 490-491.

83 Karagiannis D, Georgalas I, Ladas I, Eustratios P, Mitropoulos P: A case of subretinal neovascularization treated with intravitreal ranibizumab in a patient with idiopathic juxtafoveal retinal telangiectasis. Clin Interv Aging 2009;4:63-65.
84 Ruys J, De Laey JJ, Vanderhaeghen Y, Van Aken EH: Intravitreal bevacizumab (Avastin) for the treatment of bilateral acquired juxtafoveal retinal telangiectasis associated with choroidal neovascular membrane. Eye (Lond) 2007;21:1433-1434.

85 Konstantinidis L, Mantel I, Zografos L, Ambresin A: Intravitreal ranibizumab as primary treatment for neovascular membrane associated with idiopathic juxtafoveal retinal telangiectasia. Graefes Arch Clin Exp Ophthalmol 2009;247:1567-1569.

86 Mavrakanas N, Mendrinos E, Pournaras CJ, Salzmann J: Intravitreal ranibizumab and bevacizumab for bilateral subretinal neovascularization secondary to idiopathic juxtafoveal telangiectasia type $2 \mathrm{~A}$. Acta Ophthal mol 2009;87:930-932.

87 Maia OO Jr, Bonanomi MT, Takahashi WY, Nascimento VP, Takahashi BS: Intravitreal bevacizumab for foveal detachment in idiopathic perifoveal telangiectasia. Am J Ophthalmol 2007;144:296-299.

88 Rishi P, Shroff D, Rishi E: Combined photodynamic therapy and intravitreal ranibizumab as primary treatment for subretinal neovascular membrane (SRNVM) associated with type 2 idiopathic macular telangiectasia. Graefes Arch Clin Exp Ophthalmol 2008;246:619-621.
89 Rishi P, Rishi E, Shroff D: Combined photodynamic therapy and intravitreal bevacizumab as primary treatment for subretinal neovascularization associated with type 2 idiopathic macular telangiectasia. Indian J Ophthalmol 2009;57:241-242.

90 Berástegui L, Andonegui J: Leber's miliary aneurysm. Arch Soc Esp Oftalmol 2008;83: 669-672.

91 Yannuzzi LA, Bardal AM, Freund KB, Chen KJ, Eandi CM, Blodi B: Idiopathic macular telangiectasia. Arch Ophthalmol 2006;124: 450-460.

92 Andonegui J, Aranguren M, Berástegui L: Coats disease of adult onset. Arch Soc Esp Oftalmol 2008;83:117-120.

93 Reese AB: Telangiectasis of the retina and Coats' disease. Am J Ophthalmol 1956;42:1-8.

94 Maggi C: Leber's retinal degeneration with miliary aneurysms. Am J Ophthalmol 1963; 56:901-907.

95 Watzke RC: The spectrum of retinal telangiectasia. Trans New Orleans Acad Ophthalmol 1983;31:326-334. 